http://dx.doi.org/10.30681/23588403v14i0118

\title{
RESENHA DO LIVRO "FOTOGRAFIAS SOCIOLINGUÍSTICA DO FALAR DE FORTALEZA-CE"
}

\begin{abstract}
ARAÚJO, Aluiza Alves de (Org.); VIANA, Rakel Beserra de Macêdo (Org.); PEREIRA, Maria Lidiane de Sousa. (Org.). Fotografias sociolinguísticas do falar de Fortaleza-CE. 1. ed. Fortaleza: EdUECE, 2018. 274p.
\end{abstract}

Fábio Araújo de OLIVEIRA (UECE) ${ }^{1}$

Data de recebimento: $11 / 05 / 2020$

Data de aceite: 19/07/2021

Resumo: A presente resenha tem como objetivo apresentar o livro "Fotografias sociolinguísticas do falar de Fortaleza-CE", que traz consigo uma coletânea de artigos idealizados a partir do projeto Norma Oral do Português Popular de Fortaleza (NORPOFOR). O livro é organizado pela Prof. ${ }^{a}$ Dr. ${ }^{a}$ Aluiza Alves de Araújo (UECE), coordenadora do NORPOFOR, e suas orientandas, Rakel Beserra de Macêdo Viana e Maria Lidiane de Sousa Pereira. Após a leitura, foi possível constatar que a obra resenhada é contundente àqueles que almejam seguir pela pesquisa através da Sociolinguística Variacionista, dada a sua riqueza de referencial teórico e das possibilidades de novas pesquisas, apontadas pelos autores.

Palavras-chave: Fortaleza. Sociolinguística Variacionista. Banco de dados. NORPOFOR.

Abstract: This review aims to present Fotografias Sociolinguísticas do Falar de Fortaleza-CE (Sociolinguistic Photographs of Fortaleza Speech), a book containing a collection of articles created from the project Norma Oral do Português Popular de Fortaleza - NORPOFOR (Fortaleza Popular Portuguese Oral Norm). The authors of the book are Professor Aluiza Alves de Araújo, professor at Ceará State University and NORPOFOR Coordinator, and her mentees, Rakel Beserra de Macêdo Viana and Maria Lidiane de Sousa Pereira. Reading the book allows to realize that it is an essential work for those who aim to study and research Variationist Sociolinguistics, both because it contains a rich theoretical reference and because the authors show gapes for possible new researches.

Keywords: Fortaleza. Variationist Sociolinguistics. Database. NORPOFOR.

Idealizado a partir do projeto Norma Oral do Português Popular de Fortaleza (NORPOFOR), o livro "Fotografias sociolinguísticas do falar de Fortaleza-CE”, lançado em 13 de outubro de 2018, tem como objetivo a divulgação de pesquisas que foram feitas através do seu banco de dados. Ao lado de Rakel Beserra de Macêdo Viana e Maria Lidiane de Sousa Pereira, a prof. ${ }^{a}$ Dr. ${ }^{a}$ Aluiza Alves de Araújo (UECE), criadora e coordenadora do projeto,

\footnotetext{
${ }^{1}$ Graduando em Letras - Português/Licenciatura pela Universidade Estadual do Ceará (UECE) - Fortaleza/CE, Brasil - e-mail: fabio.oliveira@aluno.uece.br
} 
divide o livro em 7 capítulos, cujo primeiro é dedicado à divulgação minuciosa do banco de dados do NORPOFOR, e os demais, às pesquisas realizadas através do referido projeto. O livro contém, ainda, uma apresentação detalhada de todo o seu conteúdo e, ao final, há, de forma sucinta, o currículo das organizadoras e de cada autora e autor.

O primeiro capítulo, de título $O$ banco de dados NORPOFOR, foi escrito pelas organizadoras do livro e tem o objetivo de apresentar a fonte de todas as pesquisas apresentadas ao longo da obra. As autoras enfatizam a importância do corpus para um estudo sociolinguístico, pois, independente da região em que é realizado, é imprescindível uma grande quantidade de dados para analisar as características da fala do respectivo local. Após essa primeira justificativa para a construção do NORPOFOR, as autoras apresentam Fortaleza e fazem um breve resumo sobre a história da cidade, contextualizando, ainda, a realidade da capital cearense nos anos 2000, época em que a coleta foi realizada. Com 196 informantes, o NORPOFOR começou em agosto de 2003 e terminou em julho de 2006, seguindo todos os procedimentos necessários da Sociolinguística Variacionista. Os informantes foram divididos em três faixa etárias, três tempos de escolaridade, sexo e três tipos de registros; apresentados, as autoras explicam as características de cada divisão e as modalidades dos registros. Além disso, os informantes tinham que seguir alguns critérios estabelecidos, cujos também foram explanados. Baseadas nas variáveis, as autoras vão mostrando a realidade do povo fortalezense menos escolarizado. Por fim, é apresentado ao leitor o impacto do banco de dados do NORPOFOR no meio acadêmico, onde é compartilhado diversos tipos de projetos, artigos, dissertações e teses que utilizaram os dados do seu corpus.

O segundo capítulo, denominado Variação de número em predicativos do sujeito em falantes fortalezenses, de Bárbara Amaral de Andrade e Hebe Macedo de Carvalho, é responsável por abrir a coletânea de artigos presentes no livro. Utilizando de 48 informantes do NORPOFOR, os quais estão estratificados em sexo e escolaridade, as autoras buscam verificar a ocorrência de marcas do plural e a atuação de fatores linguísticos na fala do fortalezense. A revisão de literatura do artigo pode ser considerada essencial àqueles que estão em busca de pesquisas relacionadas à área, visto que as autoras apresentam diversos estudos com o mesmo teor, além de revisarem os pressupostos teóricos que dão base à pesquisa. Para a análise dos dados foi utilizado o Goldvarb X, programa já conhecido pelos pesquisadores sociolinguísticos. Os resultados mostram que as mulheres tendem a utilizar mais a forma de prestígio, além de entrar em concordância com os estudos que serviram de base teórica. 
De título Tem mais existir que haver no falar dos fortalezenses - o papel dos fatores sociais na variação dos verbos existenciais, o terceiro capítulo do livro é de autoria de Rakel Beserra de Macêdo Viana, uma das organizadoras, cujo objetivo é apresentar uma fotografia sociolinguística da capital cearense através da variação entres os verbos ter, existir e haver; para além disso, a autora também busca compreender como os fatores sociais podem influenciar no fenômeno. Para a realização da pesquisa, a autora selecionou 36 informantes, estratificandoos em sexo, faixa etária e escolaridade. Os resultados entram em concordância com as conclusões de outras pesquisas, mostrando que o verbo ter é preferido pelos homens (em especial, os mais novos e/ou os menos escolarizados), enquanto o verbo existir tem a preferência das mulheres (com destaque as mais velhas e/ou as mais escolarizadas).

Com o instigante título Sem frequentar a escola, eles concorda menos, em Fortaleza$C E$, o quarto capítulo, de Maria Lidiane de Sousa Pereira, é parte da dissertação de mestrado da própria autora (2016) e tem como objetivo apontar de que maneira o nível de escolaridade influencia na concordância verbal com a $3^{\circ}$ pessoa do plural. É importante frisar que, por não haver outro trabalho com a mesma temática, o referido artigo apresenta-se de forma significativa para os pesquisadores da Sociolinguística Variacionista. Para a realização da pesquisa, a autora selecionou 72 informantes e os dividiu de acordo com a faixa etária, escolaridade e sexo, a fim de constatar qual variante é predominantemente usada em Fortaleza (com ou sem marcação formal de concordância verbal) e qual os falantes menos escolarizados tendem a utilizar. Os resultados, além de apontarem que, de uma maneira geral, o povo fortalezense faz mais uso da variante com marcas formais, mostram que o uso das variantes é influenciado a partir do nível de escolaridade do falante, de forma que, quanto menor o nível, maior será o emprego da variante sem marcas de concordância verbal.

De Tatiane de Araújo Almeida Studart Guimarães e Aluiza Alves de Araújo, o quinto capítulo, de título Os pronomes senhor e você no falar fortalezense, analisa quais são os fatores que influenciam a ocorrência do pronome senhor $(a)$, levando em consideração o uso do pronome você; para tal, 53 informantes foram selecionados e estratificados em sexo, escolaridade e faixa etária. Levando consideração que o pronome senhor(a) configura como um sinal de respeito, poder, assimetria etc., as autoras se basearem em grandes teorias, como, por exemplo, a Teoria da Polidez (BROWN; LEVISON, 1987). Ao caminhar pelo referido capítulo, é possível perceber que as autoras precisam dar algumas pausas e abrir mão de algumas análises, uma vez que não há dados suficientes ou o objetivo diz respeito a um alvo divergente do almejado pelas autoras, o que abre um direcionamento àqueles que querem ser 
pesquisadores da área, e não sabem por onde começar. Os resultados evidenciam que o pronome você é mais utilizando, o que não significa que o pronome senhor(a) seja menos recorrente, pois sua presença é certa nos habitantes da terra alencarina, de forma que é comprovado em situações formais e, principalmente, relações assimétricas; aqui, ainda é apontado que, embora os jovens não simpatizem com a variante $\operatorname{senhor}(a)$, eles usam por uma questão de respeito.

O sexto capítulo, intitulado Nós e a gente no falar dos fortalezenses, de Marden Alyson Matos de Araújo, traz um estudo rico e detalhado acerca da variação nos pronomes de primeira pessoa do plural nós e a gente, de forma que busca compreender como os fatores linguísticos e sociais influenciam na escolha desse último. Como é possível perceber, foco se dará no a gente, portanto, o objetivo do referido capítulo é confirmar a hipótese de que esse pronome está presente, constantemente, em situações de espontaneidade e de fala popular. O autor frisa a importância que um estudo dessa magnitude tem para com a pesquisa sociolinguística que, nesse caso, é acentuado, pois trata-se de uma pesquisa inédita para cidade de Fortaleza. Para a realização da análise, após selecionar 53 informantes, o autor os estratifica em sexo, faixa etária e escolaridade. Por fim, os resultados atestam a hipótese levantada pelo pesquisador no início do capítulo, o que permitiu identificar um processo de mudança. $\mathrm{O}$ interessante, certamente, ocorre quando é afirmado que a forma pronominal a gente não pode ser tida como estigmatizada, uma vez que o seu uso é recorrente em todos os níveis sociais.

Fechando a coletânea bem sucedida de artigos, o sétimo e último capítulo instiga até o mais leigo dos leitores, tendo em vista que seu título é Rai rê se eu tô na esquina: a aspiração de /V/ no início de verbos no falar de Fortaleza-CE. Utilizando-se de 48 informantes, os quais são estratificados em sexo, faixa etária, escolaridade e tipo de registro, o objetivo da autora é avaliar como as variáveis influenciam no fenômeno, além de confirmar qual a atual situação do mesmo, uma vez que se baseia nos resultados de uma análise feita por Roncarati e Uchoa (1988). É importante lembrar que a revisão de literatura se estende a outras pesquisas. Os resultados evidenciaram que uma série de fatores podem proporcionar o enfraquecimento, tais como: pessoas mais velhas e mais novas (quando essas forem menos escolarizadas), em vocábulos monossilábicos etc. Em seguida, a autora aponta duas conclusões principais: a primeira, é de que os falantes tidos como mais velhos, tendem a manter a variante aspirada, mostrando que pode estar ocorrendo um fenômeno de mudança; já a segunda, é que, comparando os resultados com a pesquisa de Roncarati e Uchoa (1988), o uso da aspiração tem sido cada vez menor em meio ao povo fortalezense. A autora observa que essa última conclusão deve ser trabalhada em pesquisas futuras, caso haja interesse em compreender melhor o 
processo. Por fim, o capítulo é encerrado com um convite feito aos demais pesquisadores brasileiros para elaboração de novos estudos sobre o referido fenômeno, almejando tornar possível um estudo em nível macro.

Após a leitura do livro, foi possível constatar a importância da obra não só para um pesquisador fortalezense, mas para qualquer pesquisador sociolinguístico, uma vez que, ao longo do seu desenvolvimento, é mostrado uma vasta quantidade de estudos anteriores. Os autores destacam todos os seus referenciais teóricos, bem como os resultados de cada estudo apresentando, que, em sua maioria, concordam com as pesquisas apresentadas no referido livro; por ser uma caraterística recorrente em todos, isentei-me de apresentar cada um. Para além disso, o leitor pode desfrutar de uma variedade riquíssima de referências bibliográficas, um verdadeiro pote de ouro para quem está escrevendo a monografia, dissertação ou tese. Convém destacar, ainda, que a obra tem sua excelência marcada pela sua capacidade inovadora, ao trazer pesquisas inéditas, como a de Pereira (capítulo 4), Araújo (capítulo 6) e de Rodrigues (capítulo 7), além de proporcionar novos caminhos para os pesquisadores da área. O único ponto que poderia ser aprimorado, e que não necessariamente seja negativo, é o fato de a revisão ter sido realizada por apenas uma pessoa. No geral, recomendo o livro para todos aqueles que têm interesse nesta área, com a garantia de encontrar um projeto qualificado e pesquisas necessárias. 